REFERENTES TEÓRICOS Y METODOLÓGICOS DE LOS DOCENTES EN SERVICIO CON UNA PERSPECTIVA DE INCLUSIÓN EDUCATIVA: CREENCIAS Y PRÁCTICAS

THEORETICAL AND METHODOLOGICAL REFERENTS OF IN-SERVICE EDUCATORS WITH AN INCLUSIVE EDUCATIONAL PERSPECTIVE: BELIEFS AND PRACTICES

Volumen 11, Número 2

pp. 1-38

Este número se publicó el 30 de agosto de 2011

Helvetia Cárdenas Leitón

La revista está indexada en los directorios:

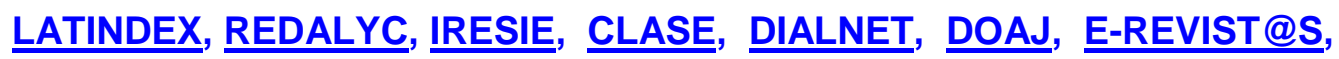

La revista está incluida en los sitios:

REDIE, RINACE, OEI, MAESTROTECA, PREAL, HUASCARAN, CLASCO 


\title{
REFERENTES TEÓRICOS Y METODOLÓGICOS DE LOS DOCENTES EN SERVICIO CON UNA PERSPECTIVA DE INCLUSIÓN EDUCATIVA: CREENCIAS Y PRÁCTICAS
}

\author{
THEORETICAL AND METHODOLOGICAL REFERENTS OF IN-SERVICE EDUCATORS \\ WITH AN INCLUSIVE EDUCATIONAL PERSPECTIVE: BELIEFS AND PRACTICES
}

\section{Helvetia Cárdenas Leitón ${ }^{1}$}

\begin{abstract}
Resumen: Desde una perspectiva de educación inclusiva se hace una lectura de los referentes teóricos y metodológicos de las docentes y los docentes en servicio graduados de una universidad pública costarricense. Se utilizó la investigación cualitativa con un método etnográfico, cuyas técnicas fueron la entrevista, la observación participante y el análisis documental. Se trabajó en dos instituciones educativas públicas, que facilitaron la investigación con docentes graduadas que tuviesen a cargo la atención de niños y niñas con adecuaciones curriculares significativas. Finalmente, se presenta entre los hallazgos, cómo las docentes pese a la mística y buenas intensiones basan sus opiniones, creencias y prácticas metodológicas en una marco teórico que responde a la diferencia alejándose, así, de los principios fundamentales de la inclusión educativa.
\end{abstract}

Palabras clave: INCLUSIÓN EDUCATIVA, DIVERSIDAD, ADECUACIONES CURRICULARES SIGNIFICATIVAS, CREENCIA, DOCENTES EN SERVICIO.

\begin{abstract}
From the perspective of inclusive education is a reading of the theoretical references and methodological teachers and in-service teachers at a public university graduates in Costa Rica. We used qualitative research with an ethnographic method, whose techniques were interview, participant observation and documentary analysis. We worked in two public educational institutions, which provided educational research by graduates that they had the attention of children with significant curricular adaptations. Finally, among the findings is presented, how the teachers despite the good intentions mystical and base their opinions, beliefs and methodological practices in a theoretical framework that responds to different distances, thus the fundamental principles of inclusive education.
\end{abstract}

Key words: EDUCATIONAL INCLUSION, DIVERSITY, SIGNIFICANT CURRICULAR ADAPTATIONS, BELIEF, IN-SERVICE TEACHERS.

\footnotetext{
Master en Psicopedagogía, Licenciada en Educación Preescolar, Licenciada en Administración Educativa, los títulos de la Universidad de Costa Rica. Profesora en la Sede de Occidente e Investigadora en el Instituto de Investigación en Educación (INIE) ambos de la Universidad de Costa Rica.
}

Dirección electrónica: hcardena19@gmail.com

Artículo recibido: 8 de mayo, 2011

Aprobado: 18 de agosto, 2011 


\section{Introducción}

La investigación y el análisis de la inclusión educativa comprende no sólo los procesos educativos en Costa Rica y la cotidianeidad en los centros educativos, sino también, la atención global de las personas, que supone un reconocimiento de las identidades con el fin de promover una experiencia democrática, caracterizada por el respeto mutuo, la cooperación, la solidaridad, la justicia y la igualdad.

La educación inclusiva requiere un cambio en la visión del mundo de todas y todos los involucrados en el hecho educativo. Los sistemas de referencia de valores y de creencias, los prejuicios, en fin, todas las características humanas del orden de la cultura deben replantearse para asumir que todas las personas, indistintamente donde se desenvuelvan, ya sea en un centro educativo, una comunidad, un país, un planeta, tienen los mismos derechos y deberes, las mismas oportunidades y deben, por lo tanto, desarrollarse dentro de un marco equitativo, justo y libre. Además, es asumir la reconstrucción de la sociedad para que todos y todas se sientan parte de ese espacio donde se nos incluya y que incluyamos, a su vez. Surgen así las adecuaciones significativas, como posibilidad para hacer el currículo accesible en igualdad de oportunidades a las personas que lo requieran.

La escuela es un espacio donde convergen diferentes sujetos con sus múltiples formas y visiones de mundo. De ahí que se considere como un espacio de producción y reproducción cultural, que conlleva a "esta vivencia misma que posee el proceso educativo en una institución escolar, que el maestro se apropia de tradiciones pedagógicas diversas y de las concepciones sobre los alumnos y sobre su trabajo que le permiten sobrevivir en la escuela" (García y Rojas, 1998, p. 34).

Por su parte, el docente se considera como el elemento esencial del proceso, ya que a él le ha sido asignada la tarea de incluir al niño o la niña dentro del espacio áulico. A pesar de sus falencias académicas, interpersonales o profesionales y con poco o ningún apoyo institucional o de capacitación, ellos se han visto comprometidos (por ley) a realizar dicho proceso, que no todas las personas entienden.

La práctica docente está determinada por los mitos, los prejuicios y las creencias de las y los docentes, mismos que se concretan en sentimientos de certeza, y en una concepción de mundo muy particular. Es decir, todo su accionar es coherente con su propio sistema de creencias, de esta forma, reproducen los mitos y los prejuicios; desconocerlos podría ser uno 
de los principales factores que permite perpetuar las prácticas educativas, especialmente, aquellas consideradas como arcaicas y poco efectivas.

Por lo anterior, el presente artículo devela los referentes teórico-metodológicos de las y los docentes en servicio graduados de una Universidad Pública costarricense, a quienes les permitan crear y recrear estrategias de atención a la diversidad desde una perspectiva de educación inclusiva, en los espacios aúlicos.

\section{Referente teórico}

\section{Aspectos fundamentales de la trayectoria histórica de la inclusión educativa en} Costa Rica

En 1937 se creó el Departamento de Higiene Mental Infantil (dependencia de Salubridad Pública y Protección Social), como institución precursora de la Educación Especial en Costa Rica, y ya en 1938 existían varias escuelas que brindaban atención a un buen número de personas con "limitaciones".

En la década de 1940, un grupo de médicos, maestros, maestras, padres y madres de familia, dirigidos por el Profesor Fernando Centeno Güell, presentaron a la Secretaría de Educación Pública (actualmente Ministerio de Educación Pública (MEP) un proyecto de decreto para el establecimiento de una escuela oficial de enseñanza especial. Para 1944 se emite la Ley No. 61, que define una política pública en educación especial, que declara de interés público la educación de los niños y niñas discapacitados (Cabezas et al. 1998).

Durante la era de la institucionalización, se crea el Patronato Nacional de Rehabilitación en 1955; en 1961, la Asociación Nacional de Rehabilitación y en 1965 varias escuelas de Educación Especial en San Carlos y San Isidro de General. Además, se fundan las primeras Asociaciones de Padres de Niños Sordos de Costa Rica.

En 1968 se formaliza la Comisión Interministerial para el Estudio de la Educación Especial. Gracias a los logros de la Comisión Centroamericana de Inválidos, donde se pusieron en marcha comisiones nacionales, que durante un tiempo ejercieron funciones coordinadoras e impulsadoras de acciones en el campo de la rehabilitación y la educación especial en cada uno de los países. En este mismo año, se construyó la Escuela para Niños Sordos, ubicada en Cartago.

La Asesoría de Problemas de Aprendizaje se creó en 1973, también el Consejo Nacional de Rehabilitación y Educación Especial y se llevó a cabo el Primer Taller sobre 
Retardo Mental. El Programa de Aulas Diferenciadas se inicia en 1974, de acuerdo con los principios de integración y normalización prevalecientes en ese periodo. Las primeras de ellas funcionaban como un aula más en la institución y estaban bajo la responsabilidad administrativa del director de la escuela, atendidas por un maestro o maestra especializado (Cabezas, et al. 1998).

En los años posteriores fue inaugurado el Centro Nacional de Rehabilitación y empiezan a funcionar las aulas-recurso, que cumplían una función de apoyo dentro del sistema educativo para la población estudiantil que requería atención específica y especializada en algunas áreas de su desarrollo.

Se logra sistematizar la integración educativa en nuestro país a partir del año 1980. Se inician acciones tendientes a lograr la adaptación de medios recreativos para personas con discapacidad, eliminándose barreras arquitectónicas y promoviendo actividades deportivas y culturales. Para 1990, Costa Rica cuenta con 19 escuelas de Educación Especial, 180 Aulas Diferenciadas, 413 Aulas Recurso, atendiendo a una cantidad aproximada de 17395 casos de niños y niñas con necesidades educativas especiales (Cabezas, et al. 1998).

Para este tiempo, el término deficiente ("discapacitado" en el contexto educativo costarricense) es sustituido por el concepto de "estudiantes con necesidades educativas especiales" (E.N.E.E.), el cual hace referencia a

aquellos alumnos que presentan dificultades de aprendizaje mayores que el resto de sus compañeros, que les impide acceder a los aprendizajes dispuestos en el currículo para su edad, por lo tanto, requieren adaptaciones de acceso y/o significativas, en una o en varias áreas del currículo. (MEP, 1997, p. 5) (Sic)

En 1996 surgió en Costa Rica la Comisión Especial Mixta, que fue nombrada por el Consejo Nacional de Rehabilitación y tenía como propósito el estudio y la propuesta de la legislación pertinente para actualizar y reformular las regulaciones existentes en el campo de la discapacidad. Esta iniciativa procuraba convertirse en el ente facilitador que generara un cambio de actitud en la sociedad y la promoción de condiciones materiales y jurídicas tendientes a eliminar la discriminación, para lograr, efectivamente, una verdadera igualdad de oportunidades para las personas en condición de discapacidad. Esta comisión mixta estaba integrada por diputados y técnicos especialistas.

Las prácticas educativas han pasado de desarrollar trayectorias asistenciales a procesos donde se respeta la individualidad de las personas, en función de sus necesidades, 
características e intereses y se pone énfasis en el entorno, como elemento que favorece o retrasa los procesos de participación de las personas con necesidades educativas especiales (Soto, 2003).

Desde 1996, en Costa Rica, diferentes organismos empiezan a gestionar proyectos que mejoren la calidad de vida de la persona asociada con discapacidad, respaldados por los principios universales de los derechos humanos. (Chavarría, 2005, p. 57). Lo anterior contribuye a iniciar un cambio en el paradigma que inspira el trabajo de las instituciones educativas, fundamentado en los derechos humanos, desde un planteamiento inclusivo, donde la persona es considerada en su integridad.

\section{Legalidad actual}

En el año 1996 se pone en ejecución la Ley 7600 a nivel nacional, dicha Ley trata de promover el desarrollo integral de la población con discapacidad, y busca la igualdad de oportunidades a nivel laboral, educativo, de adquisición de bienes y servicios, y, sobre todo, la integración a la sociedad civil como individuos activos o participantes (Asamblea Legislativa, Ley 7600: Igualdad de oportunidades)

Esta ley garantiza a todas las personas, sin diferencia de ningún tipo, el derecho a disfrutar de los principios de paz, democracia, libertad e igualdad, consagrados en la Constitución Política y las leyes de Costa Rica tal y como fueron establecidos en los principios de los Derechos Humanos, el Pacto Internacional de Derechos Económicos, Sociales y Culturales, el Pacto Internacional de Derechos Civiles y Políticos, la Convención sobre Derechos del Niño, la Convención sobre la eliminación de todas las formas de discriminación contra la mujer, el Convenio 159 de la Organización Internacional del Trabajo, el Programa de Acción Mundial para los Discapacitados, las Normas Uniformes sobre la Equiparación de Oportunidades para las Personas con Discapacidades de las Naciones Unidas. (Chacón y Vieto, 1996, p. 72)

Asimismo, esta ley se enmarca dentro de varios convenios internacionales. En el año 2001, los Ministros de Educación de Centroamérica declaran reconocer la diversidad como fundamento para la paz y el fortalecimiento de la democracia, donde las diferencias se comprendan como aporte y no como fuente de antagonismo ni de segregación, y se comprometen a seguir promoviendo la educación en general y la Educación Inclusiva en 
particular, como un derecho fundamental de la humanidad (Quesada 2003, Fraternidad 2001).

Conjuntamente, se crea el documento legal Políticas, Normativas y Procedimientos para el Acceso a la Educación de los Estudiantes con Necesidades Educativas Especiales (MEP, 1997) con la intención de orientar las políticas públicas o sociales en materia de la rehabilitación y la educación especial, institucionalizando el cumplimiento de los derechos humanos de las personas con discapacidad. Dentro de estas políticas se enmarcan las adecuaciones curriculares, que son la base para el desarrollo del proceso de inclusión en las instituciones educativas costarricenses.

Desde esta perspectiva, el sistema educativo costarricense ha ido progresando en el reconocimiento de la diversidad y de las necesidades específicas de las y los alumnos. En consecuencia, ha introducido variaciones en la organización y puesta en práctica del currículo, en el desarrollo mismo del proceso educativo y, a su vez, ha creado una serie de servicios de apoyo especializados con el fin de que las diferencias no se conviertan en desigualdades.

No obstante, en la práctica cotidiana existen todavía problemas que deben atenderse, tales como

escasez de recursos humanos especializados en los centros educativos, falta de oportunidades de capacitación actualizada para el personal, limitaciones de recursos económicos y adecuados medios de transporte, carencia de materiales educativos accesibles a los estudiantes y ausencia de infraestructura apropiada para la población estudiantil con necesidades especiales. (Programa Estado de la Nación, 2008, p. 62)

El proceso de integración educativa en Costa Rica se ha llevado de la mano con la conceptualización de la discapacidad, así como del desarrollo de estrategias pedagógicas para la incorporación de personas que poseen algún tipo de discapacidad. Desde esta perspectiva, se ha formulado el concepto de necesidades educativas especiales, así lo muestra López (2001) cuando plantea

Pese a los avances en que ha alcanzado el estudio de las dificultades de aprendizaje, en nuestro país continúa en vigencia el modelo que descansa en un currículo común y en la atención a las NEE. Este concepto deja de manifiesto la heterogeneidad de alumnos que asisten a la escuela y con ella la diversidad de respuestas que deben brindárseles, no obstante es el maestro el que desde su punto de vista personal y 
profesional (intuitivo) decide cual niño es y cual no es alumno con NEE y por tanto merecedor de trato particularizado. (López, 2001, p. 33)

En consecuencia, con la perspectiva de igualdad de oportunidades la diferencia, resulta necesario crear estrategias para la atención de las personas "con necesidades educativas especiales"; para ello, se establece la definición de las adecuaciones curriculares de la siguiente forma:

\section{Adecuación Curricular}

La adecuación curricular es un instrumento institucionalizado que se utiliza para plantear estrategias pedagógicas alternativas, para implementar la integración educativa. Este debe ser un proceso permanente de ajuste y enriquecimiento, para asegurar a la población estudiantil la funcionalidad, la pertinencia y la relevancia curricular, coherentes con las necesidades, los intereses y las experiencias de la persona que aprende y su entorno cultural y social, es decir, "La adecuación curricular no trata de elaborar un currículo alterno, sino de fortalecer el existente con aporte de la realidad inmediata, en donde el aprendizaje sea significativo, en términos de comprensión e incorporación al currículo de la realidad local y de la cultura, siempre dentro del encuadre del contexto nacional" (Mendieta, 1999 en Chavarría, 2005, p. 60).

En general, se habla de un currículo de acuerdo con la realidad del país y las particularidades de la persona y el entorno donde se desea incluir a través de "la enseñanza de destrezas utilizadas en la vida diaria, o que le permitan a las personas salir adelante en el mundo donde interactúa de la forma más independientemente posible" (Soto, 2002, p. 3).

Por su parte, el documento legal Políticas, Normativas y Procedimientos para el Acceso a la Educación de los Estudiantes con Necesidades Educativas Especiales (MEP 1997), fue creado con la intención de orientar las políticas públicas o sociales en materia de rehabilitación y educación especial, institucionalizando el cumplimiento de los derechos humanos de las personas con discapacidad, por medio de la implementación de adecuaciones curriculares de tres tipos:

- De acceso: corresponde a modificaciones o provisión de recursos especiales, materiales o de comunicación.

- No significativas: aquellas que no modifican sustancialmente la programación del 
currículo oficial. Constituyen acciones que los docentes realizan para ofrecer situaciones de aprendizaje adecuadas.

- Significativas: aquellas que consisten en la eliminación de contenidos esenciales y objetivos generales que se consideran básicos en las diferentes asignaturas y la consiguiente modificación de los criterios de evaluación.

Estas adecuaciones deben ajustarse al diagnóstico y a la evaluación del proceso de integración a través del apoyo previo, que prepara a la niña o al niño para un proceso posterior; un apoyo simultáneo, que se realiza en el aula regular y un apoyo posterior, donde se retoman temas desarrollados en el aula (Chavarría, 2005).

Las opciones para replantear la educación, pese a los esfuerzos realizados de forma general, no han tenido el impacto esperado en las aulas costarricenses. Debido, principalmente, a la poca o inadecuada incorporación de estas en el currículo educativo institucional y en la formación de los docentes: la formación de formadores.

La mayoría de los profesores manifiestan que no hay necesidad de utilizar adecuaciones curriculares o solamente de acceso. Los resultados muestran incongruencias a la atribución de adecuaciones, principalmente asociadas a riesgos psicosociales, a trastornos emocionales y del comportamiento. Los que genera una inquietud respecto al nivel de conocimiento que tienen los docentes con respecto a lo que son adecuaciones curriculares y su aplicación en el aula. (López, 2001, p. 55)

Otro aspecto significativo que se indica en el II Estado de la Educación (2008) es la ausencia de lineamientos específicos en las políticas de contratación, entre otros factores, lo que provoca que, muchas veces, se nombre personal sin formación, para evitar la pérdida de plazas, debido a la falta de personal capacitado en la región. No obstante, se registran experiencias positivas, donde la cooperación, el apoyo, la gestión compartida, el cambio y el crecimiento mutuo han sido posibles, a través de movimientos internos que tienen que ver con la actitud de todas las personas involucradas.

\section{¿Qué es la Educación Inclusiva?}

A partir de la conceptualización de la educación inclusiva, es importante reconocer como sus pilares básicos, la diversidad y el respeto por la diferencia, en la estructura pedagógica del paradigma actual. Reformar la educación en el ámbito humano exige una 
mirada diferente a la sociedad, en la cual la ejecución de los derechos individuales adquieran, dentro de un marco de acción, los principios universales de igualdad y atención a la diversidad

La inclusión no es un lugar, sino sobre todo una actitud y un valor que debe iluminar políticas y prácticas que den cobertura a un derecho tan fundamental como olvidado para muchos excluidos del planeta -el derecho a una educación de calidad-, y unas prácticas escolares en las que debe primar la necesidad de aprender en el marco de una cultura escolar de aceptación y respeto por las diferencias. (Echeita, 2006, p. 76)

La inclusión educativa se asume como esperanza y posibilidad y, en ese sentido, como una totalidad siempre en construcción, que tiene que ver con los derechos humanos (Quesada, 2003; Meléndez 2002). Este nuevo enfoque implica "cambiar el paradigma de atención y de asignación de una condición a una persona, de tal manera que no se haga una clasificación de ella, sino que, más bien se dé una caracterización de una persona con una condición específica" (Soto, 2000, p. 2).

Los procesos de inclusión educativa, según (Chavarría, 2005), representan una opción que permite a los estudiantes con necesidades educativas especiales (principalmente asociados con discapacidad), su participación en el sistema educativo regular costarricense. Los principios esenciales de esta son: el respeto por la diversidad y las diferencias, la elaboración de un currículo que posibilite la atención de todas y todos relacionándolo con su realidad, lo que implica abrirse a un método de aprendizaje cooperativo, de instrucción temática, con pensamiento crítico y buscando la resolución de problemas y la valoración auténtica. Asimismo, se debe preparar a los profesores para que enseñen interactivamente, desde una posición horizontal y debe mantenerse un apoyo continuo en las aulas, propiciar una enseñanza en equipo, fomentando una experiencia compartida y de colaboración de las personas involucradas.

Resulta relevante destacar que la inclusión educativa enfatiza la igualdad por encima de la diferencia, la igualdad inherente a todas las personas y de ahí la igualdad de derechos humanos. Así, dentro del ámbito de la inclusión se impulsa hacia un nuevo marco de pensamiento, de acción y de relaciones incluso entre las personas. En consecuencia, voces y ámbitos y, sobre todo, una nueva conciencia sobre la política y la participación social en condiciones de igualdad. 


\section{¿Cómo determinan las creencias y los estereotipos de las docentes su accionar pedagógico?}

Las docentes y los docentes construyen creencias acerca de la realidad a partir no sólo de aprendizajes formales, sino también de experiencias obtenidas mediante interacciones con el entorno social. Estas creencias, al ser difundidas por un grupo social, se convierten en un estereotipo, que va a permear no solo la forma de encarar los problemas de la vida diaria, sino también su práctica pedagógica.

Según Dewey (1989), las creencias son una afirmación o confirmación de un hecho del cual no disponemos un conocimiento seguro, que simplemente aceptamos como verdad. Desde esta posición, se entienden como prejuicios, ideas preconcebidas, no implican una actividad mental reflexiva en su formulación. De ahí la tendencia de los docentes de formular nociones simplistas que son válidos para ellos, pero que no tienen asidero científico, ni razón de ser.

Por su parte, Ortega y Gasset (1963) definen las creencias como "ideas que somos" y no ideas que pensamos. Estas no se formulan, se aluden ya operan en el fondo de nuestro pensamiento. No tenemos conciencia expresa de ellas, actúan latentes en nuestros pensamientos, conductas y expresiones"; pero son determinantes en nuestra visión de mundo, precisamente porque no somos conscientes de que actuamos con base en una falsa imagen del entorno de una persona, colectividad o sociedad. En este sentido, todo nuestro accionar se justifica en una interpretación de la realidad, con explicaciones a veces erróneas, desde una perspectiva científica de los fenómenos que ocurren a nuestro alrededor.

Las creencias, para Araya (2002, p. 44) "son proposiciones simples, conscientes o inconscientes, inferidas de lo que las personas dicen o hacen, capaces de ser precedidas por la frase". El contenido de una creencia puede: 1. describir el objeto de la creencia como verdadero o falso, correcto o incorrecto, 2. evaluarlo como bueno o malo, 3. propugnar un cierto curso de acción o estado de existencia como indeseable.

Rojas (2002), por su parte, menciona varios teóricos de las creencias como Fishbein y Bauch (1984), quienes las definen como la interrelación de un objeto con algún atributo esperado, como una dimensión de probabilidad subjetiva o conocimiento. Para Walhstrom (1982) estas son una declaración hipotética o inferencial acerca de un objeto, que los evalúa como bueno o malo y predispone a la acción, según el contexto. Wellman (1995), en su criterio, diferencia entre creencias y deseos, siendo las primeras constructos que influyen en 
el conocimiento, las convicciones, suposiciones, ideas y opiniones y los segundos se influyen en las actitudes, ansias, anhelos y preferencias.

De la Pienda (1999) expone que las creencias son una condición ontológica del ser humano, una vivencia ordinaria, no reductible a otras. A pesar de la dificultad para establecer un concepto claro de estas, las define como una evidencia, supuesto o proposición, que ni racional ni empíricamente se pueden demostrar a otros de manera que los obligue a aceptarlo.

\section{Las creencias y la ideología}

Las creencias y la ideología están muy relacionadas, pues ambas abarcan aspectos sociales e históricos particulares y solo que la segunda se concibe como un conjunto de ideas o representaciones que se imponen como verdades (creencias), pero que tienen impresa una intención o meta por parte de ciertos grupos o personas que comparten un sentido de pertenencia e identidad y desean comunicarlo o imponerlo.

La ideología se ha definido de muy variadas formas y desde diversas corrientes. Desde una posición materialista histórica, Rojas (2002) comenta a Marx y Engels, cuando analizan la ideología como falsa conciencia, como representaciones deformadas o invertidas de la realidad. Concebidas como un conjunto de significaciones (ideas, creencias, valores) que le dan sentido a la praxis social, pero que, al mismo tiempo, sirven a los intereses de los grupos o clases sociales dominantes, ya que estas representan regularmente su visión de mundo.

La determinación social de la ideología para otorgar significados y sentido a la realidad, según Gramsci, fundamenta la capacidad movilizadora o desmovilizadora de una idea, concepción o sistema de creencias. En el mismo enfoque marxista de la ideología, Rojas (2002) menciona cómo Althusser propone la existencia de un conjunto de aparatos ideológicos del Estado, que a través de su lógica propia, basada en imágenes, mitos, ideas y conceptos, se intentan reproducir o reformular las relaciones asimétricas y desiguales ya existentes. Finalmente (Poulantzas, citado por Rojas, 2002), plantea que las ideologías se fijan en un discurso relativamente coherente, en una relación del individuo con sus condiciones de existencia, investidas en una relación imaginaria.

En el ámbito de la psicología social, la ideología es considerada una de las condiciones de reproducción de las representaciones sociales. Es uno de los elementos de causalidad que interviene en la génesis de las representaciones sociales, pero esta relación de 
causalidad es de tipo circular, puesto que la representación puede modificar, a su vez, los elementos ideológicos que han contribuido a su propia formación (Araya, 2002).

La ideología será asumida desde este punto, como los aspectos ideacionales (creencias, ideas, mitos, imágenes) y las prácticas materiales (costumbres y ritos) que juegan un papel determinante en la reproducción y transformación de la realidad social (Solano, 1987).

La importancia de contemplar la ideología dentro de las creencias, o viceversa, se debe a la necesidad de reconocer las desigualdades económicas y sociales en su construcción, así como los elementos estructurantes de las mismas y la posición que ocupan en el espacio social. Es a través de la ideología, desde donde se asoman las verdaderas necesidades, intereses u objetivos de los individuos que las promueven y legitiman.

Cabe señalar que las creencias del docente subyacen en el currículo de aula a manera de currículo oculto que en definitiva es la realidad que se percibe directamente en las aulas y no siempre se articula con las opiniones externadas por las docentes y los docentes ni con las propuestas teóricas, situación que requiere la reflexión de la práctica pedagógica permanente.

\section{¿Por qué algunos estudiantes en el aula, representan un conflicto para las educadoras y los educadores?}

El currículo actual utilizado en las escuelas púbicas costarricenses se plantea por contenidos, Rojas (2002), propone una modificación que incluya programar los mismos por áreas o por preguntas generadoras. Asimismo, las estrategias de aprendizaje deberían estar formuladas a partir de los intereses y expectativas de los estudiantes de forma activa y lógica, de manera que resulte más significativo.

La adecuación curricular es un proceso de flexibilización de estrategias pedagógicas alternativas, e implementar la inclusión educativa. Estas deben desarrollarse desde un currículo abierto a un método de aprendizaje cooperativo, con una instrucción temática, donde se fomente un pensamiento crítico, de resolución pacífica de problemas e incentivando la valoración autentica de cada persona (Chavarría, 2005).

En el nuevo paradigma de inclusión, la formación de formadores juega un rol preponderante en la institucionalización del derecho humano, ya que es a través de la responsabilidad intelectual y ética de los educadores, donde se debería construir una 
conciencia crítica, que reconozca la diversidad como una característica intrínseca del ser humano, considerando las comunidades y las escuelas de acuerdo con la realidad nacional. Se deben formar profesoras y profesores críticos, conscientes de la necesidad de transformar las prácticas educativas para atender la diversidad con la meta de construir una educación inclusiva (Quesada, 2003).

Asimismo, la capacitación de los profesores y profesoras en servicio que le corresponde al Ministerio de Educación Pública en coordinación con otras entidades, debe provenir de su propia realidad, reconociendo las limitaciones que tienen los mismos, por lo tanto, el reconocimiento de sus creencias y experiencias es imprescindible. En consecuencia, las universidades deberían profundizar en su ideal del estudiante crítico, promoviendo espacios de discusión académica (conferencias, foros, textos) sobre temas controversiales contemporáneos, complementándose con una actividad práctica reflexiva, que logre acercar a los estudiantes a situaciones cotidianas y problemáticas de la realidad histórica y cultural donde viven.

El aprendizaje debe ser considerado como un proceso de cambio conceptual, además de metodológico y actitudinal, disponiendo de técnicas y recursos que permitan conocer los conocimientos de los alumnos, para modificarlos, confrontándolos con nueva información. Los procesos asociativos se apoyan en modelos miméticos de aprendizaje, mientras que los procesos constructivos tienen su origen en la toma de conciencia de los fracasos, 0 desequilibrios (Pozo, 1991).

La importancia de partir de las creencias de los educadores para desarrollar el currículo es una condición necesaria para que los educandos asuman una actitud responsable ante sus propios aprendizajes y puedan establecer puentes entre sus propios conocimientos y los nuevos (Rojas, 2002). Las situaciones donde existen estudiantes con necesidades educativas especiales, asociadas a la discapacidad en el aula, plantean dinámicas que exigen al docente una serie de competencias y conocimientos que algunas veces no poseen.

En estas situaciones, es donde emergen las creencias que tiene el educador en relación con este tema, de manera casi inconsciente busca en la memoria los elementos o referentes, que le ayuden a resolver la cotidianidad. Pero al no existir, en algunos casos, un conocimiento claro sobre esta situación, se pueden llegar a retar y modificar las creencias anteriores al respecto. 
La posibilidad de iniciar un cambio en las creencias (Rojas, 2002) supone la necesidad e importancia de que las educadoras y los educadores conozcan al menos otra hipótesis interpretativa de mundo. Promover otras experiencias de síntesis alternativas, así como un diálogo y reflexión sobre las mismas, las convierte en objeto de análisis y promueve un proceso psicológico cualitativamente superior

Es necesario que los educadores generen un clima de reflexión acerca del porqué de los contenidos culturales que imparten, por qué se incorporan unos y se desechan otros, cuáles son las fuentes de ese currículo y mediante cuáles metodologías los estudiantes reflexionan sobre estos particulares (Rojas, 2002, p. 98).

El camino recorrido en cuanto a la inclusión educativa en Costa Rica, tomando en cuenta los aciertos y los factores coexistentes, alertan respecto de que el colectivo continúa posicionado en un modelo de rehabilitación y con un amplio desconocimiento de lo que implica la diversidad, es decir, una conciencia social que imposibilita el salto cualitativo.

Al respecto, Richmond (2009, p. 85) señala

Mientras el sistema social tenga su base en una economía competitiva y no en una economía solidaria que reconozca los talentos y los esfuerzos de cada ser humano desde la diversidad y se dirija a la satisfacción de las necesidades básicas para la vida $y$, por lo tanto, al respeto de sus derechos humanos, cualquier propuesta educativa dirigida hacia la inclusión no será más que una novela romántica que muchos (as) seguirán añorando en la realidad.

Las dinámicas de aula que caracterizan la escuela costarricense no se alejan de la realidad-realidades sociales que están fuera de ellas, en todo caso, son una representación de las mismas, seres humanos diferentes e iguales en derechos. Personas que sueñan con ser y pertenecer, sentirse incluidos. Mas, como lo señalan Richmond (2009), García y Fernández (2005), y de Souza (2009), tanto la desigualdad como la discriminación se retroalimentan por medio de la producción social, las personas con alguna discapacidad representan un obstáculo para la ideología establecida; la sociedad está construida y pensada para la "normalidad", en consecuencia, lo que resulte diferente es descalificado y considerado no competitivo. 
Con una mirada similar Meléndez (2002, p. 23) indica "resulta imposible aspirar a una Educación para Todos mientras los llamados a lograrlo continúen en la búsqueda de una norma de calidad, asegurando que la diferencia interfiere negativamente en los índices de desarrollo y en los estándares de conocimiento".

Aunado a la discusión teórica, el conflicto que generan las y los estudiantes con adecuaciones curriculares significativas se debe entre otros a los siguientes aspectos:

- Los docentes son multiplicadores de los mitos y prejuicios sociales, por eso no se han dado a la tarea de hacer una verdadera reflexión acerca del tema de la discapacidad o NEE. Para algunos es una pérdida de tiempo.

- Ignorancia por parte de algunos docentes para interactuar con estos estudiantes.

- Poca o ninguna conciencia por parte de algunos docentes para atender la diversidad o para reconocer los derechos de esta población.

- Poca o ninguna disposición de algunos docentes para aprender a interactuar adecuadamente con ellos.

- Algunos han creado conciencia para atender la diversidad, pero les requiere más tiempo que el resto del grupo.

Situaciones que responden a la subjetividad de las docentes y los docentes cuando se ven enfrentados a la cotidianidad del aula, donde todas y todos los participantes no sólo poseen ritmos de aprendizaje particulares, sino realidades propias que les permiten acceder al desarrollo personal desde su prisma diverso.

\section{Metodología}

El estudio se enmarco dentro del paradigma interpretativo abordado desde el enfoque cualitativo, según Gurdián (2007, p. 67)

En la investigación cualitativa se considera que el conocimiento es producto de la actividad humana y, por lo tanto, se construye colectivamente, además al ser producto no puede desprenderse de su dimensión holística.

La investigación tomó como punto de partida el conocimiento científico y vivencial que tienen los y las docentes graduadas en servicio y que conforman la plataforma que los acerca o aleja de la implementación de la educación inclusiva. Dicha plataforma nos conduce 
irremediablemente a las experiencias de vida, de manera que se intenta llegar a las intencionalidades que dan origen a las comprensiones y a los horizontes del hecho educativo.

La investigación cualitativa, tal como lo señala Flick (2004), ofrece la oportunidad de acercarse a la realidad desde diferentes ámbitos, una de ellas es la etnografía educativa, cuyo propósito fundamental es aportar datos descriptivos de los contextos, actividades y creencias de los participantes en los escenarios educativos. Asimismo, advierte Martínez (1997), que entre las investigaciones etnográficas se pueden considerar los estudios de casos, donde predomina el uso de la observación participante. Al respecto, Sandín (2003, p.176) señala que en el estudio colectivo de casos "el interés se centra en la indagación de un fenómeno, población o condición general'.

Se enmarca, también, como estudio de casos, porque su propósito primordial fue realizar un análisis a profundidad de todo lo que ocurría en el aula con las niñas y los niños con adecuaciones curriculares significativas en dos Instituciones Educativas, los aspectos evidentes y los elementos simbólicos que acerca de la diversidad en la niñez nacieron durante el trabajo de campo, los cuales subyacen en las prácticas cotidianas de interacción entre las personas que participaron en el estudio (niñas y niños con adecuaciones significativas, docentes, directoras y asesoras regional y nacional de Educación Especial del Ministerio de Educación Pública, entre otras).

El estudio se llevó a cabo en un ambiente natural, donde se produjeron eventos y acontecimientos, a los que la investigadora principal se aproximó para comprenderlos, interpretarlos y analizarlos rigurosamente.

En relación con los datos, se recolectaron por medio de la observación participante, la entrevista en profundidad, así como el empleo de la fotografía y el análisis documental. A continuación se detalla el procedimiento:

1. Observación participante. Los propósitos fundamentales de la observación participante son: explorar ambientes, contextos, subculturas y la mayoría de los aspectos de la vida social, describir las actividades que se desarrollan, las personas que participan; comprender procesos, vinculaciones entre personas y sus situaciones o circunstancias, eventos que suceden a través del tiempo entre otras Hernández S. (2007).

Por su parte, Flick, U. (2004) indica que los rasgos principales del método son: que el investigador se mete de lleno en el campo, observa desde la perspectiva de un miembro 
pero también influye en lo que se observa debido a su participación. Además, Flick (2004, p.159) sostiene que el método de la observación "se acerca más a una concepción de la investigación cualitativa como proceso, porque supone un periodo más largo en el campo y en contacto con las personas y los contextos que deben estudiarse". Para efectos de la investigación se realizaron 2 observaciones semanales de 80 minutos durante el año lectivo 2007, específicamente entre los meses de mayo a noviembre (un total de 10 observaciones por grupo), para ello, participaron tanto la investigadora principal como su asistente de manera simultánea en cada observación. Para efectos del análisis se codificaron las observaciones de la siguiente manera: observaciones docente R (Obs, 1R), docente J (Obs, $1 \mathrm{~J})$, docente $\mathrm{G}$ (Obs, 1G) y, por último, docente $\mathrm{C}$ (Obs, 1C).

2. Las fotografías responden al uso de un medio visual con fines de investigación; al respecto, Lick, U. (2004) señala que las fotografías, las películas y el video se utilizan cada vez más como formas genuinas y fuentes de datos. El autor indica que el material visual no sólo se alcanza frente a ciertos antecedentes teóricos, sino que también se percibe e interpreta desde un punto de vista específico. En este caso particular, la investigadora observó los sujetos y tomó fotos que, posteriormente, analizó de la elección de la materia que se fotografía. Es importante señalar que no sólo se utilizó la fotografía en la observación sino en la entrevista también.

3. La entrevista, Hernández S. (2007) señala que la entrevista cualitativa es íntima, flexible y abierta. Se define como una reunión para intercambiar información entre una persona y otra u otras. Asimismo, indica que se caracterizan por: 1) el principio y el final de la entrevista no se predeterminan ni se definen con claridad, incluso pueden efectuarse en varias etapas, 2) las preguntas y el orden en que se hacen se adecuan a los participantes, 3) ser anecdóticas, 4) el entrevistador comparte con el entrevistado el ritmo y la dirección de la entrevista, 5) el contexto social es considerado y resulta fundamental para la interpretación de significados, 6) el entrevistador ajusta su comunicación a las normas y lenguaje del entrevistado, y 7) tienen un carácter más amistoso (2007, p. 673).

Se aplicó la entrevista en profundidad a las docentes, Directoras de los Centros Educativos, la Asesora Regional de Educación Especial y la Directora del Departamento de Educación Especial del Ministerio de Educación Pública (MEP), de manera que se obtuvo información para comprender sus creencias respecto de las adecuaciones curriculares significativas. 
Para la aplicación de las entrevistas se tomó en cuenta lo que señala Maxwell (1996) acerca de la reactividad, que es la influencia del investigador o de la investigadora sobre el evento o las personas estudiadas. Para Maxwell (1996) eliminar tal influencia es imposible, por lo que debe comprenderse y usarse productivamente. Por ello, en las entrevistas se evitaron las preguntas dirigidas y comprometedoras, así como aquellas que inviten a las personas a responder de una manera obvia o congraciante con el investigador o la investigadora o con otras personas. También, se consideraron los espacios, los tiempos y los escenarios más pertinentes y oportunos donde se realizaron las entrevistas. La codificación correspondiente a las entrevistas se especifica a continuación: entrevistas a docentes (EDJ, EDG, EDC, EDR) asesora Regional (EAR), asesora nacional (EAN), directora (ED1) o (ED2) y docente de problemas emocionales (EPE).

4. Análisis documental, se procedió, además, a analizar los expedientes acumulativos de las niñas y los niños con adecuaciones significativas, mismos que estuvieron disponibles para la investigadora en el momento oportuno.

Se consideró que la mejor manera de comprender lo que sucedía en las Escuelas era analizando el significado de los comportamientos que asumían las personas observadas en determinado contexto y participando en esos entornos, desempeñando roles semejantes y analizando con detenimiento lo que hacían, decían y sentían las personas participantes del estudio. Durante estas visitas se observó la totalidad de la población de estudio en sus espacios aúlicos respectivamente.

El análisis de los datos resulta uno de los aspectos de la investigación cualitativa que más claramente lo distingue de otros tipos de investigación, como los estudios experimentales, y también es el aspecto que es menos familiar a los investigadores y a las investigadoras que "venimos" a la cualitativa de otras tradiciones (Mawell, 1996). Según este mismo autor, el paso inicial en el análisis cualitativo es la lectura de las transcripciones de entrevistas antes de las transcripciones es también una oportunidad para el análisis, así como el proceso actual de las transcripciones de entrevistas o de re-escribir y reorganizar las notas de observación "crudas".

La tarea "Reducción de los datos" se llevó a cabo simplificando o "resumiendo" los datos, pero vigilando que la información fuese abarcable y manejable. Para lograrlo, se procedió a categorizar y a codificar los datos. Los datos finales se transformaron en descripciones detalladas de las creencias de las docentes en relación con las adecuaciones 
curriculares significativas, además, requirió un proceso de contrastación teórica que se sirve del marco conceptual.

Finalmente, se realizaron lecturas exhaustivas de la información con el propósito de lograr interpretaciones lo más cercanas a la realidad estudiada, y así se construyeron y reconstruyeron las respuestas a las interrogantes planteadas.

Como parte de la etapa analítica, no solo el procesamiento de los datos cobró vida, sino que, paralelamente, se estableció la devolución de la información a las docentes en cinco ocasiones, dicha estrategia se desarrolló por medio de conversaciones informales. Se presenta, a continuación, una tabla con el resumen de la información de las niñas y los niños participantes de la investigación y docentes a cargo.

\section{Tabla No.1}

Necesidades educativas especiales de las niñas y los niños participantes de la investigación y características de las docentes a cargo

\begin{tabular}{|c|c|c|c|l|}
\hline Docentes & Grado & No. de estudiantes & $\begin{array}{c}\text { Estudiantes con } \\
\text { adecuaciones } \\
\text { significativas }\end{array}$ & Necesidad educativa especial \\
\hline $\begin{array}{c}\text { Exper. } \\
\text { años }\end{array}$ & I 22 & $1-$ "VR" & $\begin{array}{l}\text { Encefalopatía no progresiva. Hipertrofia } \\
\text { cerebral por TAC. }\end{array}$ \\
\hline $\begin{array}{c}\text { Exper 19 } \\
\text { años }\end{array}$ & IV & 29 & $1-$ "ST" & $\begin{array}{l}\text { Posee compromiso cognitivo, a pesar } \\
\text { del nivel se le ubica con los contenidos } \\
\text { de segundo año. }\end{array}$ \\
\hline $\begin{array}{c}\text { Gxper 10 } \\
\text { años }\end{array}$ & I & 30 & $1-$ "'NL" & $\begin{array}{l}\text { Dificultades emocionales y de conducta. } \\
\text { Autoestima (10 años) }\end{array}$ \\
\hline $\begin{array}{c}\text { Cxper 21 } \\
\text { años }\end{array}$ & II & 31 & $1-$ "AN" & $\begin{array}{l}\text { Problemas emocionales, agresiones y } \\
\text { malas palabras (Aspeguer) }\end{array}$ \\
\hline
\end{tabular}

Elabroación propia

\section{Resultados y discusión}

Aspectos relacionados con las creencias de las docentes acerca de la capacidad de aprendizaje de las niñas y los niños con adecuaciones significativas

Al considerar que las creencias subyacen en el currículo de aula a manera de currículo oculto y determinan lo que pasa en esos espacios, a continuación se puntualizan aspectos medulares que son producto tanto de las entrevistas a las educadoras, directoras y asesoras 
involucradas en la investigación como de las observaciones etnográficas que se lograron hacer en los grupos donde se negoció y en cuyo seno había uno o dos niños o niñas con adecuaciones curriculares significativas.

Las opiniones de las docentes involucradas en la investigación, respecto de las capacidades de aprendizaje de las niñas y niños con adecuaciones curriculares significativas, resultan relativas, sobre todo si se considera que un factor determinante es la discapacidad misma. Para las educadoras es muy relativa la capacidad de aprendizaje, pues señalan, entre otros, que depende de la "discapacidad" y concuerdan, en su mayoría, que estas niñas y niños lo que aprenden realmente son habilidades adaptativas. Al mismo tiempo, aducen que se trata de entender hasta dónde llega su capacidad de avanzar en el área académica y tratar de desarrollar en todas las otras habilidades que son las que realmente los van a ayudar a vivir en este mundo tan complejo. Estas apreciaciones develan una posición paradigmática basada en la diferencia en pretender a través de los trabajos de aula nivelar a la niña o al niño "con sus iguales", posición que se aleja significativamente de los principios de la inclusión educativa, diversidad y respeto por la diferencia, sin hacer la diferencia.

En este punto resultan significativas las apreciaciones tanto de la Asesora Regional de Educación Especial como de la Directora del Departamento de Educación Especial, por cuanto ambas apuntan otros aspectos fundamentales en relación con las creencias de las docentes para la atención de niñas y niños con adecuaciones significativas.

La Asesora Regional indica "es diferente, los procesos de aprendizaje son diferentes tanto desde un paradigma inclusivo, como desde uno de integración" (EAR). Las docentes necesitan especialistas, alegan que como ellas no estudiaron eso, entonces no lo pueden abordar, de manera que esperan a que venga un especialista para que atienda a la niña o al niño que "sí lo maneje de verdad", o que lo atienda con una metodología específica. Incluso tienen el pensamiento de que las líneas de desarrollo son distintos, es decir, se sigue considerando a las niñas y niños con adecuaciones significativas como diferentes. Las docentes tienen en su imaginario que va a venir "alguien" que va a decirle cómo tienen que hacerse las cosas, semejante al estilo médico con una receta.

Hay mucho temor por parte de las docentes, por no querer causar daño, por inseguridad en que lo que puede hacer no resulte efectivo o por indiferencia. Otra de las situaciones es aquellas docentes que buscan información en diferentes medios y no la 
pueden integrar, entonces, hay una inconsistencia de las cosas que hacen, porque no concluyen nada.

Por su parte, la Directora del Departamento de Educación Especial (EAN) opina que "las creencias que manejan las docentes es que todos tienen que ir a un mismo ritmo, en definitiva es un asunto de actitud". Es decir, no se está migrando a un cambio paradigmático, sino que esta población es considerada un problema. Las niñas y niños no son considerados sujetos de derechos sino catalogados como problemas. Por eso, es que en vez de pensar y planificar metodologías para favorecer el desarrollo de las niñas y los niños, se consideran una carga que requiere mucho trabajo. "No existe una actitud positiva por parte del docente para destacar la capacidad y las otras habilidades del niño y la niña, en lugar de resaltar la deficiencia y marcar más la diferencia" (EAN).

En este sentido, se trabaja desde el paradigma de rehabilitación y especialización, el cual plantea que el problema se encuentra, exclusivamente, en la persona con discapacidad, debido a su deficiencia. Ante ello se establece que "la rehabilitación es necesaria para que la persona pueda salir adelante y la solución del problema es la intervención de profesionales especialistas, que atiendan al paciente o cliente mediante la asistencia médica, psicológica y social" (Obando y Afu Li; 1989, p. 7).

Desde esta perspectiva, el rol de la persona con discapacidad o NEE es ser "paciente o cliente" de la asistencia médica y/o psicosocial, dado que ella se mantiene en una situación de marginalidad y dependencia ante su proceso de rehabilitación y los resultados se miden por el grado de destrezas funcionales logradas o recuperadas.

Las observaciones realizadas en el aula permitieron identificar que las niñas del estudio con adecuación curricular significativa se muestran pasivas retraídas y totalmente dependientes de las docentes a su cargo.

Resulta muy interesante referirse a lo observado en una de las aulas; el hecho de que la niña "S" en la primera y segunda lección de la mañana, trabajan en Matemática, mientras la docente solicita al grupo que saquen el cuaderno de borrador o tareas para trabajar y escribe en la pizarra una serie de sumas con decimales, toma de su diario una ficha y se dirige al escritorio de "S", le explicó lo que debía hacer, para ello se agachó y explicó con un tono de voz que sólo ellas compartían, la niña inició su trabajo. Una vez que la docente se fue a trabajar con el resto del grupo "S" volteó el cuaderno hasta la última página y copió las sumas del pizarrón y se dio a la tarea de resolverlas, para hacerlo, se ayudaba con los 
dedos, algunos niños y niñas pasaban y las resolvían en la pizarra y ella -muy alegrecelebraba sus aciertos; cuando la docente desde el escritorio le preguntó cómo le iba entonces, tomó la ficha y empezó a trabajar en lo asignado; la docente se percató y se acercó, le indicó que empezara a trabajar, "entonces, puede decirse que "S" logró entender la indicación"(Obs,J5).

La anécdota es significativa, pues evidentemente la niña quería realizar el mismo trabajo que sus compañeros y compañeras, pero sabía que tenía que cumplir con otro trabajo asignado, por ello, cuando la docente se acercaba cerraba el cuaderno y doblaba la hoja donde resolvía lo de la pizarra. Esta situación evidencia no solo su deseo de hacer lo mismo que los demás, sino también que el nivel de la niña para ese contenido estaba igual que el del resto del grupo por cuanto podía resolver los ejercicios con facilidad, en consecuencia, surge la necesidad de hacer una valoración continua del avance de la pequeña. En este caso, parece obvio que con la metodología utilizada por la docente la niña se siente diferente.

\section{Elementos obstaculizadores para la atención de las niñas y los niños con adecuaciones curriculares significativas}

Las docentes señalan como elementos obstaculizadores más comunes para esta labor, a la familia, el número de estudiantes por grupo, el trabajo en papelería que representa la sistematización de la adecuación, gran cantidad de documentos $y$, algunas veces, la repetición de la información referida a la adecuación a diferentes instancias, así como la falta de recursos.

Diferente a lo expuesto por las docentes, las directoras indican que los comités de apoyo son insuficientes de acuerdo con la matrícula de las instituciones, pues se debe atender muchas adecuaciones significativas, que la capacitación, aun cuando haya disposición, requiere de mayores esfuerzos y apoyo; la resistencia por parte de las y los docentes agregan que "es comprensible", porque son grupos muy numerosos para atender el estudiantado con adecuaciones curriculares.

Señalan, además, la falta de material por parte de las Direcciones Regionales y visualizan la Asesoría Nacional como un ente que dicta directrices y nada más. De acuerdo con lo anterior, tanto la asesora regional de Educación Especial de la Región como la Directora del Depto. de Educación Especial del Ministerio de Educación Pública indican la 
actitud de las y los docentes como un elemento esencial y determinante en la aplicación de las adecuaciones significativas.

La directora del Depto. de Educación Especial del MEP, puntualiza un aspecto más preocupante aún, pues presenta la organización escolar real como un elemento obstaculizador, ella sostiene que las adecuaciones curriculares significativas no se abordan como parte del plan curricular de centro, sino como una acción más; en consecuencia, las y los docentes no se comprometen con este cometido

Los docentes no se sienten parte del Ministerio, eso cae dentro de la cultura institucional, estos son elementos que hay que tomar en cuenta. No se sienten parte del Ministerio de Educación y a pesar de que existe una plataforma con los comités de apoyo, el trabajo se centra en la especialización y las adecuaciones significativas son casi como una organización más, como el ornato, es decir en la gestión administrativa no hay una integración en cuanto al desarrollo curricular, y al no considerarse ese gran ámbito de cualquier organización curricular no impacta en el aula, el docente hace lo que el MEP solicita, y el comité de evaluación se vuelve una acción mecánica, es decir, no hay sinergia, este es el foco de atención, pero todo tiene que girar en función del desarrollo del currículo, del aprendizaje que se dé en el aula (EAN).

Según la Asesora Nacional, el Plan Doscientos los ha movilizado un poco, sin embargo, lo que piden son adecuaciones curriculares. La aplicación de la Ley 7600 vino a develar que el planeamiento curricular no responde a la diversidad. No se considera la diversidad de la población. Asimismo

uno de los mayores obstáculos en la aplicación de las adecuaciones curriculares significativas es el sistema educativo costarricense, el cual está centrado en la evaluación. Es decir, el problema radica en que el sistema no le permite al docente devolverse con los temas, tiene que continuar, y se podría hacer porque es el mismo objetivo con un grado de profundidad menor (EAN).

Durante las observaciones se pudo constatar, en efecto, que la matrícula de los grupos observados es numerosa, si se considera que lo estipulado administrativamente es que en cuanto haya una adecuación significativa se debe reducir la matrícula. Las docentes deben distribuir el tiempo de cada lección entre atender el grupo y a la niña o niño con adecuación significativa, situación que hace que en diferentes ocasiones se inclinen por el grupo, y 
asignan el trabajo al estudiante de manera individual y con menos seguimiento. Resulta una cuestión de lógica si partimos del hecho de que el trabajo de estas niñas y niños se planifica de manera diferente en relación con el del resto del grupo a excepción de "NL", es decir, no hay inclusión educativa.

Como una constante durante las observaciones, las docentes se acercan a la investigadora y le comentan la impotencia a veces de dar más ayuda a esos casos, pues el tiempo no les alcanza y para hacerlo deben atender el grupo, porque "no se pueden atrasar".

Otro aspecto significativo es que algunas de ellas señalan que requieren apoyo especializado, inclusive lo solicitaban a la investigadora, lo que se convirtió en un intercambio de pareceres y bibliografía, aunque, en todo momento, se evitó la toma de decisiones, ya que estos casos se discuten en los comités de apoyo y es en ese ámbito donde se deciden las pautas por seguir en el proceso de cada niña o niño.

Resulta interesante que, aún cuando las docentes señalan que los principales obstáculos son el número de estudiantes por grupo y la falta de apoyo de las familias, lo observado coincide con lo expresado por las asesoras a nivel regional y nacional, pues la actitud de las docentes hacia las adecuaciones curriculares significativas está cargado de mitos y prejuicios respecto de estos niños y niñas, es decir, aún cuando se muestran cariñosas, pacientes, y eficientes, en la mayoría de los casos no integran el trabajo de estos a la dinámica del resto del grupo. Ellas y ellos se atienden de manera diferente y totalmente individual, como resultado, estas niñas y niños están de alguna manera segregados del grupo, a excepción del niño "N" a quien el planeamiento se le sigue igual que al resto, porque la adecuación es por situación social y dadas sus condiciones y características es un niño que no causa dificultades en el grupo por su edad (10 años).

Cabe destacar que otro aspecto importante expresado por la asesora nacional, como elemento obstaculizador es en relación con la "organización escolar real" (EAN), es el hecho de que las adecuaciones curriculares significativas no se abordan como parte del plan curricular, sino más bien como una acción más de las responsabilidades de la escuela. Esta percepción de la Asesora no fue observada por la investigadora, pues contrario a ello las docentes y directoras participantes mostraron gran preocupación por las adecuaciones. Lo que sí resulta coincidente entre lo expresado por la asesora y lo observado es que las docentes no se sienten parte del Ministerio, pues se expresan como si de "él" recibieran "órdenes" imposibles de cumplir y que no responden, en absoluto, a la realidad del aula. 


\section{Medios o formas de transmisión o creación-recreación del conocimiento de los profesores hacia los niños y niñas con discapacidad}

En relación con los medios o formas de transmisión o creación-recreación del conocimiento de los profesores hacia los niños y niñas con discapacidad, utilizan material concreto, como rompecabezas, siluetas; también, material de refuerzo como fichas de trabajo, de actividades vivenciales y prácticas acorde con cada tema. Se utiliza además el lenguaje no verbal, específicamente lo gestual, hablar en voz alta, aunque en realidad eso depende más de las necesidades que se presentan y de la creatividad que tenga el docente.

Al respecto, la Asesora de Educación Especial de la Región señala

Ha habido una gran discusión en el tiempo, hay errores conceptuales porque trabajamos con niñas y niños con necesidades educativas especiales como si fueran diferentes. Cuando lo que varía realmente es el ritmo. Resulta que puede ser que los chicos con retraso mental puedan tener compromisos a nivel de procesar, de analizar, de clasificar, de identificar el conocimiento, pero eso no significa que no puedan hacerlo, lo llevan a un " $x$ " ritmo (EAR).

Y continúa señalando

Yo diría que es una cuestión de marco teórico o manejo teórico, el Ministerio de Educación no puede hacer nada porque los docentes llegan a trabajar con una formación definida. Otro asunto es que ya hace 10 años que esta temática se trata, no pueden las Universidades alegar que le corresponde al Ministerio de Educación todo en esta temática cuando se supone que en la formación de las y los futuros profesionales se debe asumir (EAR).

Por su parte, y no menos lamentable es el hecho de que desde el planteamiento de las normas y principios en la Ley 7600 , las niñas y niños con necesidades educativas especiales quedan invisibilizados completamente, tan desigual es la atención de los que tienen dificultades como de aquellos talentosos, pues el sistema no está listo para atenderles.

En tanto la Asesora Nacional, señala que

Las formas de transmisión o creación recreación del conocimiento de los profesores hacia las niñas y niños con adecuaciones curriculares significativas, depende de la casa de formación, y del enfoque de derechos, tenemos que reconocer que son personas con limitaciones, pero con grandes capacidades, independientemente de la 
deficiencia; y que si bien es cierto la discapacidad más difícil de trabajar son los trastornos o problemas emocionales y de conducta, no así otras manifestaciones cognitivas, físicas, también es cierto que el propósito debe ser resaltar la habilidad por encima de la deficiencia, porque todos los esfuerzos deben orientarse a potenciar el desarrollo y no volvernos al paradigma Tradicional o de Rehabilitación, sino trabajar desde el paradigma de vida independiente donde se destacan las habilidades y el desarrollo integral de las personas, lo cual es coherente con el respeto de los derechos de esta población (EAN).

En coherencia con las observaciones resulta evidente la responsabilidad con que asumen las adecuaciones significativas las docentes del estudio en cuestión, en cuanto a preparación de materiales se refiere. No obstante, aún cuando las relaciones interpersonales entre las niñas y niños observados con adecuación y las docentes responsables se caracterizaron por la atención individualizada y la empatía, en algunos momentos los niños y niñas permanecían inactivos debido a la imposibilidad de la docente para atender en forma simultánea al grupo y la adecuación.

Es decir, las docentes continúan con la idea de la atención individualizada sin una propuesta curricular de inclusividad que garantice la participación permanente de las niñas y los niños con adecuaciones curriculares significativas. Al respecto, Aguilar, (citada por Richmond, 2009, p. 87) señala "es importante tener claro que la promulgación de una política pública con la Ley 7600 no garantiza un cambio inminente en los modelos conceptuales desde los cuales se atiende a esta población". Esto nos lleva a pensar que la ley por sí misma no garantiza el cambio de actitud ni en el accionar docente, sino que la promulgación de esta es tan solo un primer paso en esta ardua labor. Pero para que se visualice el cambio se requiere un esfuerzo conjunto de todas las partes involucradas en el ámbito educativo que conlleve a un proceso de cambio en la conceptualización, percepción, actitudes y acciones concretas.

Lejos de plantear lo observado con anterioridad como una crítica destructiva, esta constituye la realidad de las aulas, por más planificación que la docente realice acerca de las actividades que emprenderá con las niñas y niños con adecuación significativa, su ritmo y particularidad no se ajustan a los tiempos estipulados por el adulto, y esa condición es necesario considerarla, tanto en el avance como en el logro de los objetivos propuestos. 
Además, se observó que el trabajo elegido por la docente para estos niños y niñas no siempre se ajustó a sus necesidades reales.

Algunas veces estuvo por debajo de la capacidad requerida y otras con un grado de dificultad muy superior; en el caso particular de las docentes observadas, es necesario señalar que las cuatro profesoras tienen más de 10 años de graduadas, y si comparamos su formación en la diversidad educativa durante sus años de especialización universitaria con los marcos teóricos actuales se puede comprender en parte el desfase existente, porque los planes de estudio con los cuales fueron formadas partían de una visión de "problema de aprendizaje" de manera que se le ofrecía una atención "remedial". Hoy se trabaja con una visión de diversidad educativa, donde todas y todos requieren una atención individualizada de acuerdo con el ritmo y estilo de aprendizaje.

Cabe rescatar, en este sentido, la importancia de la autoformación permanente de las docentes y los docentes como un desafío profesional que le permite estar actualizado, y la misión del Instituto de Desarrollo Profesional del Ministerio de Educación, cuya misión es ofrecer la capacitación requerida por el cuerpo docente de este Ministerio. Al mismo tiempo, es de un interés primordial, en la educación, propiciar una oferta educativa congruente con el desarrollo humano que se enfatice en las personas; al respecto, Bogantes (1999, citado por Fallas 2000, p. 42) define el desarrollo humano como

una corriente que aspira a la comprensión de un proceso, y desde una perspectiva humanista centrada en las personas, pretende alcanzar la plenitud humana a través del máximo desarrollo del potencial de la persona y en consideración de la condición humana como una totalidad.

Esa visión del desarrollo humano sitúa al docente en un rol de mediador, que motiva, por una parte, el desarrollo de forma individualizada y, por otra, una respuesta educativa adecuada a un colectivo de estudiantes heterogéneo, con necesidades de formación diversas e intereses personales diferentes. Esta perspectiva resulta congruente con el principio de atención a la diversidad al que hace referencia Aguilar (2000, pág. 113) donde señala que atender la diversidad escolar consiste en: "un conjunto de intervenciones educativas, que desde una oferta básicamente común para todos los alumnos, ofrece unas respuestas diferenciadas para cada uno de ellos y ajustadas a sus características individuales". Posición que no fue observada en los casos de estudio, excepto en uno, siempre las adecuaciones significativas se trabajaron de manera particular e individual. 


\section{Ajustes que realizan las docentes en el quehacer educativo para atender la diversidad individual y cultural}

Entre los materiales utilizados para atender la diversidad, las docentes utilizan fichas elaboradas específicamente para las niñas y los niños con adecuación curricular significativa.

Otra estrategia utilizada por la docente para el trabajo con "ST" es llevar a las niñas o a los niños al escritorio mientras el grupo está resolviendo un trabajo asignado en la pizarra. Por ejemplo: la docente hace una seña con la mano a "ST", la niña se va con el cuaderno para el escritorio de la profesora "J", quien trabaja con ella. Mientras la docente le explica, la niña la mira fijamente a los ojos, la maestra le pregunta y ella contesta y le dice "niña, es que me confundi", así trabajan cerca de 10 minutos (Obs, J7).

Por su parte la Directora del Departamento de Educación Especial del MEP con una visión integral del abordaje de las adecuaciones significativas, señala que "los ajustes realizados por las docentes para aplicar las adecuaciones curriculares significativas, deben ser producto de la evaluación permanente. Indica, en lo individual, debe estar ligado al contexto, y ahora tenemos diversidad de cultura, y es necesario tener cuidado, es fragmentado no es un continuo en el desarrollo de la clase de la docente, no es integral sino asignaturista, la docente debe de integrar en la práctica".

Asimismo, plantea que "la planificación en paralelo es muy común, pero inapropiada. Debería partir de un diagnóstico y ese es otro problema existente, pues creen que sólo se hace a principio de año, no utilizan la evaluación diagnóstica para orientar el proceso y el planeamiento, a pesar de que las directrices curriculares están planteadas por parte del Ministerio de Educación Pública". Indica además la Asesora Nacional, que como parte de la cutura organizaciónal de las instituciones en relación con las adecuaciones curriculares significativas:

- "El problema está en que todo es adecuación ahora. En mi opinión, ya no podemos hablar de adecuaciones curriculares sino de diversidad esa es mi perspectiva y en este Departamento nos estamos debatiendo en ello.

- Adecuación curricular se ha vuelto peyorativa.

- Es decir, la evaluación es el factor más importante si no evalúo como están los niños y las niñas, eso permitiría trabajar con la realidad. Las pruebas nacionales sólo evalúan resultados no procesos. 
- Todo es muy visual, los docentes utilizan materiales abstractos, en la propuesta invidividual debe ajustar lo necesario. Los docentes consideran que la organización del proceso determina lo que hace, se ve el niño con adecuación por allá y el resto del grupo aquí" (Sic) (EAN).

Por su parte, la asesora de Educación Especial de la Región indica que muy a su pesar no ve los ajustes, pues

sólo tiene la oportunidad de observar maestras que están siendo demandadas, arguye no tener la oportunidad de seguir procesos adecuados, sino más bien, docentes que escudan oficios, padres de familia o directores, que solicitan intervención debido a lo inadecuado de los procesos. "Los ajustes, sin embargo, más empleados son de acceso, no he logrado observar adaptaciones que tengan que ver con una real flexibilización del currículo"(Sic) (EAR).

La asesora regional señala que ha visto mucho, "cosas muy lindas en el papel", pero en la práctica es otra cosa

lo que sí he podido presenciar es que toman un objetivo del plan de estudios, verdad y se utiliza el mismo nada más que con un nivel de jerarquización del objetivo de la destreza cognitiva inferior, pero también hay que ser justo al decir, que algunas de las prácticas, para estos chicos con mayor compromiso, por ejemplo: enseñarles a lavarse los dientes, o enseñarles a aplanchar o enseñarles a caminar por las vías públicas, eso no lo puede abordar una maestra del sistema ordinario, con una cantidad de estudiantes " $x$ ", no puede llevarse (EAR).

La directora de la Escuela II, por su parte, señala que:

los ajustes que realizan las docentes están totalmente vinculados con la actitud de las mismas, aunque al principio hay un evidente rechazo, una sensación de agobio, de que ya saben lo que eso significa, lo asumen. Este es el punto álgido, pues a nivel legal hay implicaciones fatales para los docentes, la sensación de que si me equivoco, que hago un procedimiento mal me van a denunciar y cuáles son las consecuencias que ellos llevan. Además, a nivel laboral, ya se sabe que de hecho se trabaja mucho más, otro planeamiento, exámenes diferentes, crear materiales especiales, es decir hay un recargo y hay que asumirlo de alguna manera. Además, el niño o la niña con 
adecuación curricular que se revela porque no quiere hacer trabajos diferentes a sus compañeros, no quiere un trato diferenciado. $Y$ el tipo de niño que nos desconcierta con el comportamiento o desarrollo, por ejemplo un Síndrome de Asperger, nos pierde, no sabemos cómo actuar con él. También están las adecuaciones de niños extranjeros y su adecuación no es tanto porque no ha aprendido sino por el retraso sociocultural que tienen, un niño de 13 años que está ingresando a primero grado, que no ha tenido ningún contacto con la cultura escolar y obviamente como niño se siente muy mal en primer grado, y necesitamos enseñarle a leer y a escribir, podríamos pasarlo a un sistema como el aula abierta, pero no todos los niños quieren ir allá, no todos los papás los pueden mandar (ED2).

La compañera de apoyo de una de las instituciones, quien colabora con las adecuaciones significativas, opina que los ajustes que realizan las docentes consisten en el planeamiento propiamente y la metodología, aslmismo, preparan materiales como fichas, y lecturas. "Lastimosamente, a veces lo que es material concreto tal vez cuesta que lo preparen, como resúmenes diferentes, fichas especiales, por ejemplo, para trabajar fracciones, las operaciones, y algún material concreto". (Sic)

Las docentes entrevistadas que atienden a las niñas y niños con adecuaciones curriculares significativas señalan como ajustes para atender a esta población: distribuir el tiempo lo mejor posible, indagar en cuanto a materiales y los recursos que se requieran, solicitar mayor apoyo al padre de familia, también mejor distribución del espacio con el que se cuenta. El material concreto, también es necesario ajustar el planeamiento, porque debe responder a las necesidades de cada niño y niña con adecuación, fichas, carteles, juegos y las adaptaciones necesarias en el momento que surja alguna situación de disciplina.

Conviene señalar que durante las observaciones realizadas se pudo constatar el uso de materiales especialmente diseñados para las niñas y los niños con adecuaciones curriculares significativas, aunque no suficientes, pues en reiteradas ocasiones éstas personas debieron esperar a que la docente concluyera con el trabajo grupal donde tanto la niña como el niño no estaban incluidos. 


\section{Elementos teóricos y metodológicos que le parecieron innecesarios en su formación universitaria}

La opinión de las docentes respecto de los elementos teóricos y metodológicos innecesarios en la formación universitaria es diversa; no obstante, se concentra entre otros aspectos en la confección de material y murales que "no se utilizan", determinación de dificultades y elaboración de planes individuales; la última opinión resulta contrastante con los señalamientos de las mismas docentes respecto de las fortalezas y debilidades en la formación para la educación inclusiva durante sus años universitarios, pues indican como debilidad la falta de formación "especializada", en cuanto a la detección de problemas específicos. Otro elemento que consideran innecesario en su formación, y en el cual coincidieron, es el trabajo conjunto con el hogar, en su lugar lo que primó en este cuestionamiento es que lo recibido en la Universidad constituye la base fundamental para el trabajo de aula.

Por su parte, las personas que se desempeñan en puestos administrativos expresan opiniones quizá más apegadas a la teoría actual para la atención de las adecuaciones significativas, como el caso de la profesora "I", encargada de problemas emocionales de la Institución Educativa 1, quien opina

yo considero que falta mucho en lo que a formación se refiere, tal vez por parte del MEP para las docentes porque se plantean las adecuaciones, especialmente, las significativas, pero a veces no se da como un asesoramiento a las docentes regulares y muchas de ellas le comentan a uno que no saben cómo abordar algunos casos, especialmente cuando son más complejos (EPE).

\section{Atención diferenciada entre niños con y sin discapacidad}

La atención diferenciada entre niños y niñas, con y sin discapacidad, está muy relacionada con lo discutido anteriormente respecto de los ajustes que realizan las docentes para atender las adecuaciones curriculares significativas.

Las personas involucradas en la investigación que ocupan puestos administrativos, opinan que a veces

La adecuación sobre todo cuando es en área social, lo que se logra más es con las conductas adaptativa que propiamente con la parte académica y eso es más funcional 
que lo otro, porque como usted dice, un niño que tiene problemas a nivel neurológico, eso no va a ceder (EAN).

También opinan que

La atención diferenciada depende mucho de cómo la docente lo aborde y los padres y madres; es una realidad todos perciben el trato diferente, los trabajos que no coinciden y la atención distinta que ofrece la docente, sin embargo conforme pasa el tiempo lo empiezan a ver de manera diferente. Si yo pudiese cambiar algo trabajaría en la actitud de las docentes, porque aunque hay maestras que no tienen el conocimiento lo buscan, tratan de investigar piden ayuda, están pendientes de cómo ayudar a ese niño. Definitivamente es una sensibilidad de la situación del niño y de tratarlo igual que a los demás, solo darle el apoyo que necesita (EAN).

\section{Fortalezas y debilidades en la formación para la educación inclusiva}

De acuerdo con la investigación, se pudo detectar que en el campo de la formación académica para la educación inclusiva existen debilidades tales como: "Todo niño tiene derecho a integrarse a la educación, pero con políticas adecuadas en cuanto a espacio sobre todo y a cantidad de niños con situaciones especiales. En muchas ocasiones estos niños sufren dificultades en cuanto al ritmo de aprendizaje y socialización lo que dificulta su desempeño. Una fortaleza es que le permite la socialización y más seguridad al niño, pero en cuanto a desventajas el sistema no ofrece las condiciones adecuadas para el trabajo con ellos" (Obs, G6). Como se evidencia en la opinión de esta docente hay una confusión de términos, particularmente, utiliza los términos inclusión e integración como sinónimos

Trabajar con menos estudiantes para poder atenderlos mejor y en general al grupo, y en cierta forma el tiempo que usted le dedica a estos estudiantes es tiempo que debería estar trabajando con el grupo, y si usted tiene todos los chiquitos como computadoras programados y que todos fueran iguales entonces usted sabe que todos van a responder igual, pero no es así (Obs, R1).

Importante rescatar que en el fondo de esta expresión se evidencia un estereotipo asociado con la diferencia por cuanto el considerar que la niña en este caso, requería de más tiempo para resolver los trabajos, intervenía directamente para el avance grupal. 
Fortalezas en las que el niño no se ve o se menosprecia, se socializa con el resto del grupo. Debilidades, "el gran desgaste que tenemos nosotras como docentes, considero que es demasiado el trabajo que hay, estar moviéndose de un lado para otro, estar atendiendo 2 grupos completamente diferentes y tener que hacer exactamente lo mismo por un niño que por 28, eso desgasta, lleva tiempo y hasta recursos financieros, porque usted tiene que buscar el material y un montón de cosas" (Obs, C1).

Por su parte, las administrativas tanto de las direcciones de las instituciones educativas participantes de la investigación como la Asesora Regional y Nacional opinan que empiecen a hablar de barreras para el aprendizaje y dejen atrás el concepto de necesidades educativas especiales, y no confundan, porque no es lo mismo, la transición de lo que se construyó hace años era pertinente para ese momento hoy no lo es. Es preciso, como opina la Asesora Regional, "Ilegar a la educación inclusiva, la educación para todos no es nueva sino eliminar barreras para el aprendizaje desde el punto de vista de la administración financiera, curricular, es decir, equilibrado para que se pueda atender de manera pertinente" (EAN).

\section{Estrategias novedosas aplicadas para atender las adecuaciones significativas}

Las docentes, quienes tienen niñas y niños con adecuaciones curriculares significativas en sus aulas, indican que para atenderles de manera novedosa utilizan entre otras, mucha motivación, creatividad, apoyo y la atención necesarias con los recursos disponibles y sobre todo con la sensibilidad necesaria para que esta población no se sienta rechazada. Actividades de reconocimiento de habilidades y esfuerzo mostrado por los niños, coorperación en el trabajo en clase y apoyo mutuo entre los niños y niñas.

Según la Asesora Nacional, se trabaja a través de proyectos piloto, centrados en diferentes ámbitos, más de apoyo del docente en el aula, no algo aislado: "las benditas aulas de apoyo no deben existir el servicio de apoyo de problemas de aprendizaje, que dentro del aula con el docente, ese es el enfoque novedoso es decir la mediación tienen que ser con todos y todas, porque de lo contrario estamos excluyendo" (Sic) (EAN).

\section{Consideraciones finales}

Los referentes teóricos y metodológicos de las docentes y los docentes graduados en servicio de una Universidad Pública determinan cuanto acontece en las aulas, y dimensiona, 
sin pretender agotar el tema, el abordaje que se hace en los espacios aúlicos en estudio acerca de la inclusión educativa en niñas y niños con adecuaciones curriculares significativas. A continuación, se presentan una serie de consideraciones finales que pretenden la reflexión pedagógica y un aporte en la temática de la inclusión educativa.

$\checkmark$ Los mitos y los prejuicios de las docentes estudiadas, en relación con la capacidad de aprendizaje de los niños y las niñas con adecuaciones curriculares significativas, son el producto de un análisis de conceptos subyacentes en su práctica de trabajo diario, es decir, que más que un discurso teórico, las afirmaciones presentadas en la presente investigación son el producto de un sistemático proceso de observación y análisis de conceptos.

$\checkmark$ La educación, no ha incorporado suficientes elementos que la redireccionen hacia la atención a la diversidad, y ha dejado descubierta la promoción de las diferencias como característica del entorno, mientras que sí ha insistido en la homogenización y masificación de la educación en detrimento de esta población. Como lo señala Meléndez (2002, p. 22) "toda nuestra educación, en forma más estricta los mecanismos de evaluación y normas de promoción y graduación, está fundamentada sobre medidas de normalidad [...] que por su naturaleza, son totalmente contrarias a las intenciones del respeto a la diversidad y por lo tanto, contrarias a los valores democráticos".

$\checkmark$ Las docentes estudiadas continúan basando sus opiniones y prácticas metodológicas en un marco teórico que responde a la diferencia y no a la diversidad, en consonancia clara con lo planteado por el Ministerio de Educación Pública (2005, p. 14) el alumno con necesidades educativas especiales "es aquel estudiante que presenta condiciones de aprendizaje diferentes o dificultades en el aprendizaje mayores que el promedio de los alumnos, lo que le dificulta o impide acceder al currículo que le corresponde por su edad, de forma que requiere para compensar dichas diferencias, adecuaciones en una o varias áreas del currículo".

$\checkmark$ La práctica de trabajo diario devela que el concepto de adecuación curricular significativa, que asumen las docentes del estudio, está cargado de prejuicios, especialmente, porque la atención individualizada se hace extensiva a todos los momentos de la jornada, no solo en aquellos casos donde amerita ese apoyo, es decir, no se hace efectiva la inclusión educativa, en consecuencia, el tratamiento resulta 
discriminatorio y excluyente.

$\checkmark$ La práctica docente es el marco por excelencia para develar las creencias del maestro, debido a que el discurso teórico-conceptual que expresan las docentes en relación con los niños y las niñas con adecuación curricular significativa no siempre se traducen en estrategias o propuestas tendientes a la inclusión educativa de dicha población.

$\checkmark$ En relación con los elementos obstaculizadores en el estudio, se señala el número de estudiantes, las familias que en gran número utilizan las adecuaciones significativas como sinónimo de promoción, el trabajo administrativo, planeamiento, exámenes, seguimiento al expediente y materiales de apoyo, en síntesis, recargo de trabajo docente y administrativo sin apoyo.

$\checkmark$ Desde los puestos administrativos y técnico-docentes, se visualiza la actitud de la docente como el elemento obstaculizador de más peso, pues si la docente se dispone a trabajar con las adecuaciones curriculares significativas, lo puede hacer, pero si su actitud es negativa por más asesorías y capacitaciones no funciona. Además, por parte de estas funcionarias se indica la falta de estímulos, matrícula, materiales y tiempo para planificar.

$\checkmark$ Existe un contraste entre las opiniones de las docentes del estudio y las Asesoras Regional y Nacional con respecto a las adecuaciones curriculares significativas, para las primeras el trabajo es arduo y no reciben apoyo, y en muchos casos desconocen el manejo adecuado de las particularidades que presentan las niñas y niños que reciben, y para las segundas es cuestión de actitud, las docentes no se sienten parte del Ministerio de Educación, lo conciben como el ente que ordena las acciones por seguir, sin cuestionárselas.

$\checkmark$ La práctica educativa de algunas de las docentes observadas está cargada de mística y buenas intenciones, pero se aleja de los principios fundamentales de la inclusión educativa.

$\checkmark$ La individualización y el trato separado como estrategia metodológica por excelencia, utilizadas por las docentes para las adecuaciones curriculares significativas observado, exigen un análisis profundo del tema de la inclusividad, especialmente de cara a futuras reformas educativas.

$\checkmark$ Resulta necesario analizar el manejo de las adecuaciones curriculares significativas que realizan las docentes, especialmente, de cara a las propuestas de educación 
inclusiva. Para ello, es imperativo investigar en profundidad el concepto o conceptos que tienen las futuras y los futuros docentes respecto de la población con adecuaciones curriculares significativas, con el fin de construir una práctica pedagógica pertinente con la diversidad educativa que garantice la equidad y el respeto.

$\checkmark$ Ofrecer cursos de actualización profesional a las personas graduadas que incluyan temáticas relacionadas con el análisis de la práctica docente, especialmente, en la atención a la diversidad, a través de proyectos de Extensión Docente, y o espacios de reflexión en Seminarios y Simposios, sería una respuesta a la situaciones que surgen como parte del proceso de investigación.

$\checkmark$ Es necesario incorporar suficientes elementos que redireccionen la educación hacia la atención a la diversidad, donde personas no solo diferentes culturalmente, sino aquellas con diferencias individuales como quienes tienen alguna discapacidad, puedan tener acceso a los espacios áulicos regulares, esto permite comprender las diferencias como componente inmanente del entorno.

$\checkmark$ Revalorar el quehacer educativo es urgente, pues es el espacio donde se construyen, reconstruyen y reproducen muchas de las prácticas culturales que nos acompañarán toda la vida. Pero esa revaloración no puede realizarse autónomamente, todas las personas que participan en el hecho educativo tienen la responsabilidad de apropiarse de las propuestas de la educación inclusiva, para que logren luego, en forma orgánica, incorporar a su quehacer esa perspectiva.

$\checkmark$ Investigar el rol que se le concede a las niñas y los niños con adecuaciones curriculares significativas dentro del currículo escolar costarricense, con el afán de contar con otras informaciones que orienten futuras reformas educativas en lo relativo a la inclusividad y atención a la diversidad y con ello lograr una práctica curricular más pertinente y ajustada a la realidad en cuanto a matrícula.

$\checkmark$ Por último, resulta indispensable un análisis de la práctica docente, a la luz de los conceptos subyacentes que en ella se entremezclan, con el objetivo de poder evidenciar cambios reales que solo se logran con la identificación clara de las creencias propias. Iniciativa que se puede materializar a través de un proyecto de extensión docente 


\section{Referencias}

Aguilar, Luis Ángel. (2000). De la integración a la inclusividad. La atención a la diversidad: Pilar básico en la Escuela del Siglo XXI. Buenos Aires: Espacio.

Araya, Sandra. (2002). Las representaciones Sociales: ejes teóricos para su discusión. Cuaderno de Ciencias Sociales. San José: FLACSO.

Cabezas, Grace, Camacho, Flory, Gamboa, William, Madrigal, Gabriela, Morera, Paola. (1998) Análisis del proceso de integración de los niños con necesidades educativas al primer y segundo ciclo de la educación general básica en la dirección regional de enseñanza de San Ramón. Memoria de seminario de graduación para optar por el grado académico de Licenciatura en Ciencias de la Educación, con énfasis en educación primaria. San José: Universidad de Costa Rica.

Castro, Ericka. (1998) Evaluación de la aplicación de las políticas de educación especial y su relación con la Ley de Igualdad de Oportunidades. Informe final para optar al grado de Magíster con énfasis e administración educativa. San José: Universidad Costa Rica.

Chacón, Lilliana, Vieto, Nancy. (1996) Lineamientos administrativos para la inclusión de niños con necesidades educativas en el aula regular a nivel de preescolar. Tesis para optar al grado de Licenciatura en Ciencias de la Educación con énfasis en Administración Educativa. San José: Universidad de Costa Rica.

Chavarría, Andrea. (2005) Implicaciones de la integración escolar de la persona con necesidades educativas especiales sobre el desarrollo de la práctica docente en el aula las necesidades de formación y capacitación docente de la dirección regional de San José. Tesis de licenciatura en educación especial. San José: Universidad de Costa Rica.

Consejo Nacional de Rectores. (2008). Segundo Estado de la Educación. San José, Costa Rica: Estado de la Nación.

De la Pienda, Jesús. (1999) Filosofía de las creencias. Revista de filosofía de la Universidad de Costa Rica, 37 (92).

Echeita, Gerardo. (2006). Educación para la inclusión o educación sin exclusiones. Madrid: Narcea.

Flick, Uwe. (2004). Introducción a la investigación cualitativa. Madrid: Morata.

García, Alix, Fernández, Aleida. (2005). La inclusión para las personas con discapacidad: entre la igualdad y la diferencia. Revista Ciencias de la Salud, 3 (2), 235-246.

García, Nidia, Rojas, Marta. (1998) La capacitación del maestro desde la perspectiva etnográfica: una experiencia a partir de la investigación en el aula. Revista Educación, 22 (1), 33-43. 
Gurdián, Alicia. (2007). El paradigma cualitativo en la Investigación Socio-Educativa. Costa Rica: IDER

López, Katia. (2001). Teorías intuitivas docentes sobre los alumnos y alumnas con necesidad educativas especiales. Tesis para optar por el grado de Licenciatura en Psicología. San José: Universidad de Costa Rica.

Martínez, Miguel. (1997). Comportamiento humano: nuevos métodos de investigación. México: Trillas.

Meléndez, Lady. (2002). Implicaciones de la diversidad personal y cultural en el escenario educativo centroamericano. Ciclo de conferencias 2002. Centro Nacional de Recursos para la Inclusión Educativa 11 noviembre 2002. San José, Costa Rica.

Ministerio de Educación Pública. (1997). Políticas, Normativas y Procedimientos para el Acceso a la Educación de los Estudiantes con Necesidades Educativas Especiales. San José: MEP.

Ortega y Gasset, José. (1987). Ideas y creencias. Obras completas. Revista de Occidente, 5, 381-408.

Parrilla, Angeles. (2002). Acerca del origen y sentido de la Educación Inclusiva. Revista de Educación, 327, 11-29.

Pozo, Juan Ignacio. (1991) Teorías cognitivas del aprendizaje. Madrid: Morata.

Quesada, Rolando. (2003). ¡Dejad que las diferencias vengan a mí! Universidad y educación inclusiva. Revista Educación, 27 (2), 27-38.

Richmond, Viviana. (2009). El camino de la inclusión de personas con necesidades educativas especiales en Costa Rica: aportes para la discusión. Revista Educación, 33 (2), 81-93.

Rojas, Grace. (2002). Creencias que construyen los sujetos que participan del desarrollo de los procesos de aprendizaje y enseñanza, en una escuela primaria. Tesis de doctorado en Educación. San José: Universidad de Costa Rica.

Sandín, Paz. (2003). Investigación Cualitativa en Educación. Madrid: Mc GrawHill.

Solano, Mario. (1987). La psicología de las clases sociales. San José: Editorial Alma Mater.

Soto, Ronald. (2000). Más allá de la clasificación y la comprensión de los conceptos de los grupos de discapacidad: La persona. Revista de Educación, 24 (2), 135-149.

Soto, Ronald. (2003). La inclusión educativa: una tarea que le compete a toda una sociedad. Revista Actualidades Investigativas en Educación, 3 (1).

Stainback, William y Susan. (1999). Aulas Inclusivas. España: Narcea. 